\title{
Mann-Whitney Test
}

National Cancer Institute

\section{Source}

National Cancer Institute. Mann-Whitney Test. NCI Thesaurus. Code C53247.

The Wilcoxon-Mann-Whitney test uses the ranks of data to test the hypothesis that two samples of sizes $\mathrm{m}$ and $\mathrm{n}$ might come from the same population. 